Revista Española de Filosofía Medieval, 4 (1997), pp. 189-201

\title{
LA PERVIVENCIA DEL CORPUS TEOLÓGICO CICERONIANO EN ESPAÑA
}

\author{
Ángel Escobar \\ Universidad de Zaragoza
}

\section{RESUMEN}

Los llamados tratados «teológicos» de Cicerón (De natura deorum, De divinatione, De fato y la traducción parcial del Timeo platónico) fueron muy apreciados a partir de la antigüedad tardía y tuvieron gran influencia en la literatura europea medieval. Sin embargo, la transmisión de estas obras filosóficas parece haber sido en España muy escasa -y fundamentalmente indirecta- hasta el siglo XIV, adquiriendo una relevancia sólo algo mayor durante los siglos XV y XVI, debido seguramente a las dificultades que suponía adaptar el escepticismo del pensamiento ciceroniano a la ortodoxia cristiana, a pesar de los ensayos humanísticos en esta dirección.

Palabras clave: Cicerón, Teología, Escepticismo, Ortodoxia cristiana, Humanismo.

\section{ABSTRACT}

The transmission of Cicero's theological works in Spain.The so-called 'theological' works of Cicero (De natura deorum, De divinatione, De fato, and his partial translation of Platonic Timaeus) were highly valued from late antiquity on, and had a very rich influence on European medieval literature. However, the transmission of these philosophical dialogues seems to have been very scarce and mainly indirect in Spain until the fourteenth century, only a little more significant in fifteenth and sixteenth century, probably because of the difficulties in adapting the sceptical basis of the Ciceronian thought to the Christian orthodoxy, in spite of the humanistic attempts in this direction.

Key words: Cicero, Theology, Christian orthodoxy, Humanism.

Suele llamarse «teología ciceroniana» al grupo de tratados redactados por Marco Tulio Cicerón entre el 45 y el 44 a.C. acerca de la divinidad y su relación con el género humano (De natura deorum, De divinatione y De fato). La denominación puede servir también para aludir a la traducción ciceroniana del Timeo de Platón, elaborada a mediados del 45 y que había de integrarse en un diálogo de carácter cosmológico que el arpinate no llegó a realizar. ${ }^{1}$ Estas obras guardan una

1 La traducción de Cicerón, que tan sólo comprendía parte del original platónico (27d-47b), también recibe el título de De universitate en algunos testigos de la tradición manuscrita. 
estrecha relación entre sí dentro del proyecto filosófico de su autor. ${ }^{2}$ En la primera, compuesta de tres libros, Cicerón se sirve de tres interlocutores: el epicúreo Veleyo (I, 18-56), el académico Cota (I, 57-124, III) y el estoico Balbo (II). Una vez ha expuesto cada uno su teoría acerca de la naturaleza divina, el autor — que apenas interviene como personaje en el diálogo— se decanta por la opinión de Balbo como la más «verosímil» (III, 95: «ad veritatis similitudinem [...] propensior»). ${ }^{3}$ En el De divinatione, Quinto, hermano del orador, expone sus ideas favorables a la adivinación desde una perspectiva fundamentalmente estoica (I), siendo rebatido en el libro segundo por el propio Marco Tulio, que vuelve así a poner en práctica el método dialéctico característico de la escuela académica a la que decía pertenecer («disputatio in utramque partem»). Desde el punto de vista del contenido, esta obra está íntimamente ligada a la primera, en cuanto que la adivinación sólo resulta posible en principio si los dioses existen y si, desde su providencia, manifiestan el futuro al ser humano. ${ }^{4}$ Finalmente, la parte conservada del De fato, diálogo mantenido entre Cicerón e Hirtio, muestra cómo la idea de destino está también íntimamente relacionada con la existencia de la adivinación -ambas nociones se basan en el concepto estoico de simpatía- y, en última instancia, con la existencia de la divinidad. ${ }^{5}$ El Timeo platónico, por su parte, ofrecía una compleja explicación cosmológica del mundo -no siempre entendida por el propio Cicerón, a causa de su «rerum obscuritas» (Fin. II, 15)- que no tardó en influir poderosamente en la cultura occidental, sobre todo a través del comentario elaborado por Calcidio en el siglo IV. ${ }^{6}$

Es muy probable que Cicerón concibiera este grupo de obras con una intención «pedagógica», más que polémica. En ellas ofrecía a sus conciudadanos romanos, escasamente pertrechados todavía en materia filosófica, abundante información de interés: noticias acerca de las distintas escuelas helenísticas y sus precedentes (gracias, por ejemplo, a doxografías como la de Nat. I, 25-41), gran cantidad de datos sobre filosofía y religión antiguas en general, noticias de interés científico, citas de poe-

2 Para un panorama general sobre la obra filosófica de Cicerón véase J.G.F. Powell, «Cicero's philosophical works and their background», en J.G.F. Powell (ed.), Cicero the philosopher: Twelve papers, Oxford, 1995, pp. 1-35. Para el texto latino de nuestras obras son recomendables las siguientes ediciones: W. Ax, M. Tulli Ciceronis [...] De natura deorum post O. Plasberg edidit..., Stuttgart, 2. ${ }^{\text {a ed., }} 1980$ (1933; 1911-17); R. Giomini, M. Tulli Ciceronis [...] De divinatione. De fato, Timaeus edidit..., Leipzig, 1975.

3 Son especialmente útiles para el estudio de esta obra las siguientes ediciones comentadas: A.S. Pease, M. Tulli Ciceronis De natura deorum, I-II, Cambridge (Mass.), 1955-58 (con reseña de O. Gigon, Gnomon, 34 [1962], pp. 662-676 [= Studien zur antiken Philosophie, Berlín-Nueva York, 1972, pp. 349-364]); W. Gerlach y K. Bayer, M. Tullius Cicero. Vom Wesen der Götter, Múnich-Zúrich, 3. ed., 1990 (1. a , 1978).

4 Cf. A.S. Pease, M. Tulli Ciceronis De divinatione libri duo, Darmstadt, 1963 (= University of Illinois Studies in Language and Literature, 6 [1920]. pp. 161-500; 8 [1923], pp. 153-474); S. Timpanaro, Marco Tullio Cicerone. Della divinazione, Milán, 1988; Chr. Schäublin, M. Tullius Cicero. Über die Wahrsagung, Múnich-Zúrich, 1991.

5 Cf. A. Yon, Cicéron. Traité du destin, París, 1944; D.P. Marwede, A commentary on Cicero's De fato, Baltimore, 1984; R.W. Sharples, Cicero: On fate (De fato) and Boethius: The consolation of philosophy (Philosophiae consolationis) IV.5-7, V, Warminster, 1991.

6 La obra de Calcidio estuvo, al parecer, escasamente representada en las bibliotecas españolas y, además, en manuscritos de procedencia foránea: $c f$. J. Fontaine, Isidore de Séville et la culture classique dans l'Espagne wisigothique, I-III, París, 1959 y 1983 (III), p. 1130, n. 658, 9; para el tema también se utilizaron fuentes de carácter menos complejo: cf., por ejemplo, J. Lara, «La creación del mundo en la poesía barroca: de la tradición neoplatónica a la ortodoxia contrarreformista», en A. Gallego, A. Soria y N. Marín (eds.), Estudios sobre literatura y arte dedicados al profesor Emilio Orozco Díaz, II, 1979, pp. 241-262. 
sía romana arcaica, etc. ${ }^{7}$ Se hacía, por lo demás, en un estilo deliberadamente cuidado por parte de su autor, que pretendía así, además de conciliar en cierto modo filosofía y elocuencia, implantar en la literatura latina la rica tradición dialógica griega representada por su admirado Platón. ${ }^{8}$

\section{PERVIVENCIA ANTIGUA Y MEDIEVAL DEL CORPUS}

Los diálogos de los que aquí nos ocupamos se vieron avalados muy pronto por la auctoritas ciceroniana, convirtiéndose así en una especie de enciclopedia filosófico-religiosa de amplia difusión. ${ }^{9}$ Cuando, a finales de la antigüedad, entre los siglos segundo y cuarto, los autores cristianos examinaron los pecios de la literatura pagana, para ver en qué medida eran todavía rescatables y si resultaban asumibles como praeparatio evangelica, el corpus ciceroniano atraviesa su primera prueba de fuego. Las obras son leídas por Tertuliano, ${ }^{10}$ Minucio Félix, ${ }^{11}$ Arnobio, ${ }^{12}$ Lactancio, ${ }^{13}$ san Agustín ${ }^{14}$ y otros muchos autores, vivamente interesados además por el modelo literario que los

7 Pese a los ensayos realizados en el mismo terreno por algunos contemporáneos suyos, como por ejemplo Varrón, autor de unas Antiquitates rerum divinarum ( $c f$. B. Cardauns, M. Terentius Varro. Antiquitates rerum divinarum, I-II, Maguncia-Wiesbaden, 1976); sobre el ideario varroniano en materia religiosa -comparable en buena medida con el de Cicerón- $c f$. igualmente G. Lieberg, «Die theologia tripertita in Forschung und Bezeugung», ANRW, I, 4 (1973), pp. 63-115.

8 Cf. D. Marsh, The Quattrocento dialogue. Classical tradition and humanist innovation, Cambridge (Mass.)Londres, 1980, pp. 1-23.

9 Para un panorama sumario de la pervivencia de nuestras obras desde la antigüedad (Valerio Máximo, Plinio, etc.) hasta época moderna, aunque siempre con las precauciones necesarias (posibles fuentes intermedias en muchos casos), $c f$. Pease, Nat., pp. 52-61, Div., pp. 29-37. Entre los cristianos influyeron notablemente, por ejemplo, las noticias contenidas en el De natura deorum acerca del evemerismo (I, 118-119, etc.; cf. Evhemeri Messenii reliquiae, ed. M. Winiarczyk, Stuttgart-Leipzig, 1991, testim. 14), del que se usó profusamente en un primer estadio para combatir el politeísmo pagano (cf. J. Seznec, Los dioses de la antigüedad en la Edad Media y el Renacimiento [= La survivance des dieux antiques, París, 1980], tr. J. Aranzadi, Madrid, 1983, p. 20, Evhemerus..., testim. 69 A [Lactancio, Div. Inst. I, 11, 44-48]).

10 Cf. J.-C. Fredouille, Tertullien et la conversion de la culture antique, París, 1972, p. 68, n. 4, quien considera verosímil una utilización directa del De natura deorum, pese a las dudas expresadas al respecto por Y. Opelt, «Ciceros Schrift De natura deorum bei den lateinischen Kirchenvätern», Antike und Abendland, 12 (1966), pp. 141-155.

11 Utiliza tanto el De natura deorum como el De divinatione para su Octavius.

12 Un resumen de sus argumentos tomados del De natura deorum puede verse en Arnobe. Contre les gentils, I, ed. H. Le Bonniec, París, 1982, p. 47, n. 2.

13 Lactancio, el famoso Cicero Christianus, fue, además, fundamental para la conservación de parte del libro III del De natura deorum, ya que manejó un ejemplar completo de la obra, anterior, por tanto, al arquetipo de nuestra tradición manuscrita, y que habría sido mutilado por obra de paganos ( $c f$. J. Guillén, «Introducción a la teología de Cicerón», Helmantica 27 [1976], pp. 193-259, esp. 257) 0, más verosímilmente, de cristianos (cf. Pease, Nat., p. 1.142). Sobre el testimonio de Lactancio respecto a Cicerón -de reserva, en general- $c f$. V. Buchheit, «Cicero inspiratus - Vergilius propheta? Zur Wertung paganer Autoren bei LaktanZ», Hermes, 118 (1990), pp. 357-372. Por lo demás, la prevención de este autor ante el riesgo de confusión entre paganismo y cristianismo no era excepcional: cf., por ejemplo, M. Testard, «Jérôme et Ambroise. Sur un 'aveu' du De officiis de l'évêque de Milan», en Y.-M. Duval (ed.), Jérôme entre l'occident et l'orient. XVI centenaire du départ de saint Jérôme de Rome et de son installation à Bethléem. Actes du Colloque de Chantilly (septembre 1986), París, 1988, pp. 227-254, esp. 232.

$14 C f$. Pease, Div., pp. 31, 34, n. 1. Sus abundantes citas de nuestras obras se hallan inventariadas en M. Testard, Saint Augustin et Cicéron, I-II, París, 1958, en II, pp. 134-135; cf. también I, pp. 206-215. Los testimonios más relevantes de Minucio Félix, Arnobio, Lactancio y S. Agustín han sido reunidos por W. Gerlach y K. Bayer, o.c., pp. 472-549. 
diálogos ciceronianos ofrecían para la elaboración de una rhetorica Christiana cada vez más necesaria. ${ }^{15} \mathrm{Su}$ veredicto parece haber sido, como en otros casos, bastante unánime y concluyente: la teología ciceroniana se aproximaba ciertamente al espíritu cristiano, pero su autor no estaba movido por él, de modo que la virtud reflejada en sus obras era pura apariencia, por no estar basada en un verdadero conocimiento de Dios que le diera sentido. ${ }^{16}$ Cicerón, por tanto («homo longe a veritatis notitia remotus, expers caelestium litterarum» y provisto de una mera «imago sapientiae», según palabras de Lactancio), era un filósofo, pero no un profeta. ${ }^{17}$ Su teología, sin llegar a considerarse nociva para el pensamiento cristiano, era completamente prescindible desde un punto de vista doctrinal, máxime cuando se disponía de fuentes estoicas y neoplatónicas de mayor garantía teórica que el vago pragmatismo académico de corte ciceroniano. ${ }^{18}$

Como es natural, el medievo europeo también recibe la herencia teológica de Cicerón. Entre sus primeros representantes cabe destacar a Hadoardo, autor del florilegio ciceroniano conservado en un manuscrito de mediados del siglo IX (Vat. Reg. Lat. 1762) con excerpta de varias obras filosóficas, previamente expurgadas de los pasajes de contenido menos «cristiano». ${ }^{19}$ La selección manejada por Hadoardo coincide en buena medida con la que circuló por Europa desde mediados de ese mismo siglo y que suele contenerse en la mayoría de nuestros manuscritos conservados. Se trata del llamado «corpus de Leiden» (recogido fundamentalmente en el Voss. Lat. F 84 y el Voss. Lat. F 86), que reúne ocho obras: De natura deorum, De divinatione, Timaeus, De fato, Topica, Paradoxa Stoicorum, Lucullus y Leges. ${ }^{20}$ Son numerosos los autores medievales de los siglos $\mathrm{XI}$ a XIII —algunos de ellos bien conocidos en la península — que, una vez establecido este canon, leen

15 Del tema se ha ocupado por ejemplo J. Fontaine, Aspects et problèmes de la prose d'art latine au III' siècle. La genèse des stylles latins chrétiens, Turín, 1968.

16 La ambigüedad del discurso ciceroniano fue percibida incluso desde el propio paganismo, que propuso la destrucción de unos libros «quibus Christiana religio comprobetur» (cf., por ejemplo, Arnobio, Adv. nat. III, 6-7, Testard, I, p. 224, Pease, Nat., p. 54; según este último autor, p. 56, n. 2, la obra ciceroniana sirvió de praeparatio evangelica malgré Cicerón, lo cual es, por supuesto, una suposición inverificable y, a nuestro entender, poco verosímil).

17 Cf. V. Buchheit, o.c., pp. 360, 362, 364 .

18 Ya condenado por S. Agustín en su Contra academicos, pero que seguirá recibiendo reproches hasta bien entrado el siglo VI, como muestra el anónimo Contra philosophos: $c f$. M.L. Colish. The Stoic tradition from antiquity to the early middle ages. II: Stoicism in Christian Latin thought through the sixth century, Leiden-Nueva York-CopenhagueColonia, 2. ${ }^{\text {ed., }} 1990\left(1 .{ }^{2}, 1985\right)$, pp. 290-297; se trata de una obra dialógica de origen italiano, en cinco libros, inspirada básicamente en la Civitas Dei agustiniana; entre los muchos interlocutores paganos del cristiano Agustín, aparece Cicerón, como defensor de la religio civilis característica de la tradición romana (p. 292) y de la concepción estoica del destino, basada en la conciliación efectuada por Crisipo entre necesidad y contingencia (p. 294).

19 Cf. Pease, Div., p. 33, n. 202. Sobre su selección (Luc., Sen., Div., Fat., Amic., Leg., Nat., Off., Parad., Tim., Tusc. y De or.) y la labor realizada en ella $c f$. M. Manitius, Geschichte der lateinischen Literatur des Mittelalters, I-III, Múnich, 1964-65 (1911-31), en I, pp. 478-483; Ch. H. Beeson, «The collectaneum of Hadoard», CPh, 40 (1945), pp. 201-222; P.L. Schmidt, Die Überlieferung von Ciceros Schrift De legibus in Mittelalter und Renaissance, Múnich. 1974, pp. 134-152; B. Munk Olsen, «Les classiques latins dans les florilèges médiévaux antérieurs au XIII siècle (II)», RHT, 10 (1980), pp. 115-164, esp. 143-144; D. Ganz, Corbie in the Carolingian Renaissance, Sigmaringen, 1990, pp. 92-97. Sobre este tipo de materiales en general $c f$. recientemente J. Hamesse, «Parafrasi, florilegi e compendi», en G. Cavallo, C. Leonardi y E. Menestò (eds.), Lo spazio letterario del medioevo, I. Il medioevo latino, III: La ricezione del testo, Roma, 1995, pp. 197220; B. Munk Olsen, «La trasmissione dei testi nei secoli XI e XII», ibídem, pp. 375-414.

20 Cf. R.H. Rouse, «De natura deorum, De divinatione, Timaeus, De fato, Topica, Paradoxa Stoicorum, Academica priora, De legibus», en L. D. Reynolds (ed.), Texts and transmission. A survey of the Latin classics, Oxford, 1986 (1983), pp. 124-128. 
las obras teológicas ciceronianas y las citan, como Pedro Abelardo, Juan de Salisbury, ${ }^{21}$ santo Tomás, Roger Bacon, etc.

\section{EL EXAMEN HUMANÍSTICO}

Cuando lo que solemos llamar humanismo se consolida en Italia y en el resto de Europa, Cicerón seguía siendo ante todo el princeps eloquentiae alabado desde tiempos de Quintiliano, el Tulio de «rica lengua» al que se había de referir Juan de Mena (Laberinto de Fortuna, 119b) ${ }^{22} \mathrm{Su}$ vasta producción filosófica, sin embargo, pese a admirarse en su conjunto - tras los pasos de Dante, que veía en Cicerón un maestro de la «filosofica famiglia» (Inf., IV 141)—, ${ }^{23}$ se había escindido ya en dos bloques: el de los tratados de carácter predominantemente moral (De finibus bonorum et malorum, Tusculanae disputationes, De senectute, De amicitia, De officiis, etc.), ${ }^{24} \mathrm{de}$ enorme éxito por su gran utilidad (literatura sapiencial en general, espejos de príncipes, etc.), y, por otro lado, el que configuraban nuestros tratados teológicos, de mucha menos fortuna, pese a la entusiasta reivindicación de los mismos practicada en Italia por Petrarca, ${ }^{25}$ Boccaccio, Bruni, etc. ${ }^{26}$ Estos autores -marcando una tendencia que llegará hasta la edad moderna, a través de Erasmo y otros muchos- procurarán rescatar el testimonio de Cicerón, conscientes de que en su obra teológica había abundante material útil para la apologética cristiana, como la defensa del dios estoico que aparece en el libro segundo del De natura deorum, desde una perspectiva prácticamente monoteísta, ${ }^{27}$ la enérgica condena de la superstición contenida en el libro segundo del $D e$

21 Acerca de sus fuentes (el De officiis sobre todo, en el caso de Cicerón) cf. Juan de Salisbury, Policraticus, ed. M.A. Ladero, M. García y T. Zamarriego, Madrid, 1984, pp. 33-35.

22 Es la nisma imagen tópica que atestigua, por ejemplo, el propio Cervantes en su Quijote (II, 22, 32).

23 Cf. A. Ronconi, s.v. «Cicerone», en U. Bosco (dir.), Enciclopedia Dantesca, Roma, 2. ${ }^{a}$ ed., 1984 (1. $\left.{ }^{a}, 1970\right)$, pp. 991-997, que muestra cómo el poeta utilizó especialmente el De amicitia, así como el De off., Sen. y Fin. Sobre pervivencia de Cicerón en Italia, en general, $c f$. las monografías clásicas de Th. Zielinski, Cicero im Wandel der Jahrhunderte, Leipzig, 4. ${ }^{\text {a } e d ., ~} 1929$ (1. ${ }^{\text {a }}$ 1897), y B. Weil, 2000 Jahre Cicero, Zúrich-Stuttgart, 1962.

24 Constituye un caso especial el Sueño de Escipión, que circuló como parte independiente del libro sexto del De republica, con gran éxito en época tardoantigua -sobre todo a raíz del comentario de Macrobio- y durante todo el medievo (también en Bizancio, como demuestra el hecho de haber sido traducido al griego, junto al comentario de Macrobio, por Máximo Planudes); al respecto cf. P. Courcelle, «La postérité chrétienne du Songe de Scipion», RÉL, 36 (1958), pp. 205-234; B. Munk Olsen, «Quelques aspects de la diffusion du Somnium Scipionis de Cicéron au Moyen Âge (du IX ${ }^{\mathrm{e}}$ au XII ${ }^{\mathrm{c}}$ siècle)», en Studia Romana in honorem P. Krarup, Odense, 1976, pp. 146-153.

25 Cf., por ejemplo, A. Buck, Die Rezeption der Antike in den romanischen Literaturen der Renaissance, Berlín, 1976, p. 118; J.A. Maravall, «La estimación de Sócrates y de los sabios clásicos en la Edad Media española», en Estudios de historia del pensamiento español. I: Edad Media, 3. ${ }^{\mathrm{a}}$ ed., 1983 (2. ${ }^{\mathrm{a}}, 1973$, RABM, 62; 1. ${ }^{\mathrm{a}}$, 1957), pp. 269-330, esp. 278 279; F. Rico, El sueño del humanismo (de Petrarca a Erasmo), Madrid, 1993, pp. 138-141. Poco intportó, en este sentido, que el descubrimiento de las Cartas a Ático decepcionara profundamente al genio de Arezzo (cf. A. Gómez Moreno, España y la Italia de los humanistas. Primeros ecos, Madrid, 1994, p. 251, n. 438).

26 La tendencia a la «cristianización» de Cicerón llegará al propio Erasmo, cuyo Convivium religiosum ya había sido traducido al español por Ruiz de Virués en 1529 (cf. Rico, o.c., pp. 135-136).

270 acaso mejor «panteísta», al concluirse con una «decepcionante» identificación de la divinidad con el mundo (cf. P. Dronke, Intellectuals and poets in medieval Europe, Roma, 1992, p. 164). 
divinatione, ${ }^{28}$ la defensa del libre arbitrio del De fato, claramente percibida ya por san Agustín, ${ }^{29}$ etc. Estos diálogos ciceronianos, también apreciados desde el punto de vista literario pese a su no siempre modélica latinitas, permitían además abordar el problema -por entonces pujante- de la relación que había de establecerse entre elocuencia y filosofía, y, por otra parte, brindaban un apoyo estimable para toda una serie de argumentos característicos de la mentalidad humanística, ${ }^{30}$ como el del nuevo racionalismo (basado, por ejemplo, en el principio del consensus omnium, tan empleado por Cicerón ${ }^{31} \mathrm{o}$ el de la exaltación de la naturaleza y del ser humano que la preside. ${ }^{32}$

No habría resultado extraña, en nuestra opinión, una presencia significativa de este corpus filosófico en España, por muy sui generis que fuera nuestro humanismo (o, mejor dicho, por muy limitado que fuera el acceso de nuestros eruditos a las humaniores litterae). Sin embargo, no parece haber sido así. Cicerón, que nunca llegó a ostentar en la tradición hispánica el rango de figuras como la de Sócrates, Platón, Aristóteles o Séneca, ${ }^{33}$ fue ampliamente conocido y estimado en nuestra península, pero su pervivencia quedó limitada a unas cuantas obras, entre las que no es frecuente encontrar las teológicas, al menos según lo que se desprende del somero análisis que aquí ofrecemos.

28 La condena de la superstición pagana -como degradación de la verdadera revelación profética admitida por la Iglesia- todavía resuena en M. Menéndez Pelayo, Historia de los heterodoxos españoles, I-II,Madrid, 4. ${ }^{\text {a }}$ ed.. 1986-87 (1. ${ }^{\text {, }}$, 1880-82), en I, p. 281, o, como recuerda E.A. Ramos Jurado, «Un filósofo ante la adivinación, Jámblico de Calcis», SPhV,

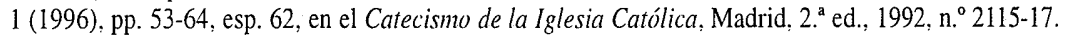

29 Sobre el tratamiento del tema en la literatura cristiana cf., por ejemplo, D. Amand, Fatalisme et liberté dans l'antiquité grecque. Recherches sur la survivance de l'argumentation morale antifataliste de Carnéade chez les philosophes grecs et les théologiens chrétiens des quatre premiers siècles, Amsterdam, 1973 (Lovaina, 1945). Sobre el tema en la literatura española, en general, cf. O.H. Green, España y la tradición occidental. El espíritu castellano en la literatura desde El Cid hasta Calderón (= Spain and the western tradition. The Castilian mind in literature from El Cid to Calderón, Madison, 1963-66), tr. C. Sánchez, I-IV, Madrid, 1969, en II, pp. 239-312 y 313-376; J. de D. Mendoza Negrillo, Fortuna y providencia en la literatura castellana del siglo XV, Madrid, 1973; F. Díaz Jimeno, Hado y fortuna en la España del siglo XVI, Madrid, 1987. Poco después de aparecer el M. T. Ciceronis de fato liber Petri Rami praelectionibus explicatus (1550), el humanista portugués Aquiles Estazo publicó unas In Ciceronis librum De fato notae, Lovaina, 1551, según recuerdan M. Menéndez Pelayo, Bibliografia hispano-latina clásica, III: Cicerón - Historia Augusta, ed. E. Sánchez Reyes, Santander, 1950, p. 82, y J. Guillén, «Cicerón en España», en Atti del I Congresso internazionale di studi.ciceroniani, Roma, aprile I959, II, Roma, 1961, p. 259 (sobre el «ciceroniano» De fato et libero arbitrio de Ginés de Sepúlveda cf. ibidem, p. 273).

30 Algunas ideas de interés al respecto en A. Michel, «Épicurisme et christianisme au temps de la renaissance: quelques aspects de l'influence cicéronienne», RÉL. 52 (1974), pp. 356-383; «Humanisme et anthropologie chez Cicéron», $R E ́ L, 62$ (1984), pp. 128-142.

31 También es significativo al respecto el frecuente uso humanístico de una referencia como la de Nat. I, 10 ( $c f$. Marsh, o.c., p. 11: «From Bruni through Poggio to Valla the rejection of abstract authority is couched in Cicero's paradigmatic deprecation of Pythagorean allegiance [...], now invoked against the Aristotelian dogmatism of ignorant Schoolmen»). La anécdota del magister dixit ya fue recordada «según el testimonio de Tulio» por Juan de Salisbury, Policraticus V, 12. Ciertas dudas respecto a la bondad de la razón expresó, no obstante, Cicerón, por ejemplo en Nat. III, 65-68.

32 Desde la plenitud de la dignitas hominis, siempre a medio camino entre la divinitas y la feritas: $c f$. , por ejemplo, Nat. II, 148, 153, 158-160, así como Green, o.c., III, p. 159, Rico, o.c., pp. 175, 178-180.

33 La referencia esencial al respecto sigue siendo Maravall, o.c., esp. pp. 292, n. 83, 295, n. 95, 302; cf. asimismo M. ${ }^{2}$ J. Lacarra, «La imagen de los filósofos en los textos gnómicos del siglo XIII», en J.M. Ayala (coord.), Actas del I Congreso Nacional de Filosofía Medieval, Zaragoza, 1992, pp. 45-63. 


\section{VARIA FORTUNA DE LA TEOLOGÍA CICERONIANA EN ESPAÑA}

\subsection{Transmisión textual}

Son escasos, por no decir inexistentes, los trabajos dedicados al estudio de la pervivencia hispánica de estos tratados. Poco es lo que puede espigarse en la clásica contribución de Menéndez Pelayo, a propósito de la obra ciceroniana en su conjunto, 0 en investigaciones más recientes. ${ }^{34}$ Desde el punto de vista textual, parece verosímil que estas obras estuviesen en nuestras bibliotecas desde muy antiguo, ${ }^{35} \mathrm{y}$, en cualquier caso, desde época medieval, ${ }^{36}$ aunque una utilización extensa con fines eruditos no pueda documentarse en ningún momento. En cuanto a textos impresos, la presencia del corpus teológico ciceroniano en las prensas autóctonas parece haber sido nula, ${ }^{37}$ aunque

34 Cf. M. Menéndez Pelayo, Bibliografía hispano-latina clásica. II: Catulo - Cicerón..., ed. E. Sánchez Reyes, Santander, 1950, pp. 199-431; Bibliografía..., III: Cicerón - Historia Augusta, pp. 7-284; nada nuevo aporta a nuestro tema J. Vallejo, Papeletas de bibliografia hispano-latina clásica, Madrid, 1967; cf. igualmente Guillén, «Cicerón en España», pp. 247-282; C.J. Classen, «Cicerostudien in der Romania im 15. und 16. Jahrhundert», en G. Radke (ed.). Cicero, ein Mensch seiner Zeit. Acht Vorträge zu einem geistesgeschichtlichen Phänomen, Berlín, 1968, pp. 198-245, esp. 218-228; M. ${ }^{2}$ R. Lida, La tradición clásica en España, Barcelona, 1975, pp. 375-376; D. Briesemeister, «Cicero in Mittelalter und Humanismus, VI», en R.-H. Bautier y R. Auty (eds.), Lexikon des Mittelalters. II: Bettlemesen bis Codex von Valencia, Múnich-Zúrich, 1981-83, cols. 2.072-73.

35 La cuestión resulta, como siempre, difícil de determinar. Como sintetizó M.C. Díaz y Díaz, «La transmisión de los textos antiguos en la península ibérica en los siglos VII-XI», en Settimane di studio del Centro italiano di studi sull'alto medioevo, XXII: La cultura antica nell'occidente latino dal VII all'XI secolo, 18-24 aprile 1974, Spoleto, 1975, en I, pp. 133-178, esp. 174, pudo haber más manuscritos clásicos de los que pensamos, pero durante estas primeras etapas «la técnica de enseñanza y la afición al método exegético de sentencias, catenas y glosas trabadas tendían cada vez más a usar de preferencia manuales y resúmenes, aunque las bibliotecas ofrecieran al lado las obras mismas clásicas cuyos comentos y extractos se utilizaban y aprovechaban al máximo. Las antologías, las compilaciones y las obras de cuestiones circulaban con más éxito que los amplios tratados y los escritos en que se basaban». $C f$. también R. Gibert, «Antigüedad clásica en la Hispania visigótica», en Settimane..., II, pp. 603-652.

36 Puede verse un amplio censo en Pease, Nat., pp. 61-85; Div, pp. 604-619. Entre los relativamente escasos manuscritos españoles con nuestras obras (para los escorialenses -algunos en posesión de Zurita, a quien se refiere Menéndez Pelayo, Bibliografía..., III, pp. 114-117- cf. G. Antolín, Catálogo de los códices latinos de la Real Biblioteca del Escorial, III [L.I.2.-R.III.23.], Madrid, 1913; Catálogo..., IV [S.I.1.-Z.IV.22. - Vitrinas - Índice de materias. Índice de miniaturas]. Madrid, 1916; y, en general, L. Rubio, Catálogo de los manuscritos clásicos latinos existentes en España, Madrid, 1984), es de especial interés el R.I.2, que, según L.D. Reynolds, «The transmission of the De finibus», IMU, 35 (1992), pp. 1-30, esp. 14-15, fue escrito en Francia en el XIV y estuvo en la biblioteca papal de Avignon, perteneciendo así a Pedro de Luna, que lo llevó a su castillo de Peñíscola; en 1424 fue entregado por Clemente VIII a Alfonso V de Aragón, de donde pasó a través de Zurita y los cartujos del Aula Dei al Escorial. También merece especial atención el Matrit. 9116, del que se ha ocupado L.D. Reynolds, «Petrarch and a Renaissance Corpus of Cicero's philosophica», en O. Pecere y M.D. Reeve (eds.), Formative stages of classical traditions: Latin texts from antiquity to the Renaissance. Proceedings of a conference held at Erice, 16-22 october 1993, as the 6th Course of International School for the Study of Written Records, Spoleto, 1995, pp. 409-433; escrito en Italia a finales del XIV, contiene Nat., Tim., Div., Tusc., Par., Fin., Ac. post., y fue adquirido por la Biblioteca Nacional en el siglo XVIII; no es autógrafo petrarquista, pero las anotaciones -sobre todo en Tusc. y Fin.-- proceden del humanista italiano (sí son autógrafas las anotaciones del manuscrito de Troyes, Bibl. Munic. 552 [Off., Tusc., Nat., Div., Fat., Am., Sen., Parad., Ac. pr., etc.], en el que están ampliamente anotados los tratados Nat. y Div.)

37 Cf. Pease, Nat., pp. 88-106; Div., pp. 620-634; F. García Craviotto, (coord., dir.), Biblioteca Nacional. Catálogo general de incunables en bibliotecas españolas, I, Madrid, 1989, pp. 246-260 (n. ${ }^{\circ} 1591,1611,1620-1623,1627-1628$, 1660,1664 ); hay referencia de las ediciones impresas del XVI (pocas españolas en proporción) en el Index Aureliensis. Catalogus librorum sedecimo saeculo impressorum, prima pars, VIII, Baden-Baden, 1989, pp. 11-333. 
cabe afirmar igualmente que no faltaron en nuestras bibliotecas abundantes ejemplares de ediciones foráneas, frecuentes desde la aparición de la princeps en Roma (1471). ${ }^{38}$

El panorama en este terreno resulta, en suma, bastante desolador. La primera edición latina de nuestros textos publicada en España no llega hasta bien entrado el siglo XVIII, a cargo de Juan Antonio Melón (Madrid, 1797; volúmenes X [Nat.] y XI [Div., Fat.]) ${ }^{39}$ y las únicas traducciones completas que hemos podido rastrear son la del De natura deorum realizada por Gil de Taboada (1782) y las de Nat., Div. y Fat. publicadas en la Biblioteca Clásica dirigida por Menéndez Pelayo (vol. III, Madrid, 1883, y vol. V, Madrid, 1884). ${ }^{40}$

\subsection{Pervivencia literaria}

Las citas de nuestro corpus por parte de autores peninsulares, desde la época de san Isidoro, no han sido especialmente frecuentes, y siempre resulta difícil determinar si proceden de una lectura directa o son más bien de puro acarreo ${ }^{41}$ La lectura medieval de estos tratados -practicada con cierta profusión en el resto de Europa- no deja de ser una suposición fundada en el caso de la tradición hispánica, y lo que se desprende de un primer cotejo superficial de nuestra literatura de la época es que no parece haberse producido en ningún momento un uso sistemático del Tulio teólogo. ${ }^{42}$

No obstante, merecen cierta atención las citas que revelan que las obras se conocieron en nuestra tradición relativamente temprano, aunque fuera de manera indirecta y con una finalidad esencialmente práctica (es decir, sermonaria). Baste recordar al respecto el interesante testimonio de Juan Fernández de Heredia ${ }^{43}$ o el de Juan García de Castrojeriz (med. XIV) y su traducción glosa-

38 Hay una edición veneciana de ese mismo año. Sobre la actividad traductora en otros países europeos $c f$. R.R. Bolgar, The classical heritage and its beneficiaries, Cambridge, 1977 (1954), pp. 527 (trad. alemana del De fato por J.G. von Oderheim, 1491-97, no impresa y hoy perdida), 528 (trad. francesa del De natura deorum por L. de la Boderie, París, 1581). 529 (trad. italiana del De divinatione por G. Giustiniani, 1549). Nuestras obras no parecen haber pertenecido nunca al canon escolar, pese a posibles conatos tan tempranos como los reseñados por Bolgar, ibidem, pp. 197-198.

39 Cf. Menéndez Pelayo, Bibliografía... II, pp. 239-259.

40 Ibídem, pp. 412, 428-431; la versión del De divinatione y la del De fato, ambas en el vol. V, son obra de D. Francisco Navarro y Calvo, canónigo de la Metropolitana de Granada. Hay una traducción española del De natura deorum a cargo de Francisco de P. Samaranch (1970), dependiente de la inglesa de Rackham, y de esta misma obra y del De divinatione a cargo de J. Pimentel (UNAM).

41 Cf. Pease, Div., p. 32, F.-J. Lozano, San Isidoro y la filología clásica, León, 1982, pp. 86-93. Su utilización de estas obras ciceronianas no supone necesariamente que las manejara de manera directa: cf. Fontaine, Isidore de Seville, pp. 745-747, Díaz y Díaz, o.c., p. 139.

42 El espíritu de la praefiguratio está en la base, por ejemplo, del Setenario de Alfonso X (cf. Maravall, o.c., p. 280); el rey se refiere a Cicerón como el «filósofo» (cf., por ejemplo, Primera Crónica General de España, caps. 117, 122), pero en el ámbito alfonsí se conoce igualmente la retórica ciceroniana. Como recuerdan Menéndez Pelayo, Bibliografía..., II, p. 199, M.C. Díaz y Díaz, Libros y librerías en la Rioja altomedieval, Logroño, 2. ${ }^{\text {ad., }} 1991$ (1. $\left.{ }^{2}, 1979\right)$, p. 274, Alfonso $X$ toma prestado en 1270, entre otros libros, un comentario de Macrobio al Sueño de Escipión.

43 Así en su Libro de las actoridades o Rams de flores; sobre la figura de este autor y su labor literaria en general cf. J.M. Cacho Blecua, «Introducción a la obra literaria de Juan Fernández de Heredia», en I Curso sobre lengua y literatura en Aragón (Edad media), Zaragoza. 1991, pp. 171-195; A. Montaner, «Una aproximación a Juan Fernández de Heredia», Turia, 35-36 (1996), pp. 253-283, esp. 269. Citamos la obra -con ligeros retoques ortográficos y diacríticossegún J. Nitti, J. y L.A. Kasten, The electronic texts and concordances of medieval Navarro-Aragonese manuscripts prepared by..., Madison, 1997, edición a la que nos ha dado acceso amablemente J.M. Cacho, a quien debemos también la totalidad de las referencias de los siglos XIV y XV mencionadas en este trabajo. 
da del De regimine principum de Egidio Romano. ${ }^{44}$ Significativamente, ambas fuentes, que beben de materiales latinos afines, recogen la versión de uno de los pasajes de colorido más «cristiano» de todo el De natura deorum (Nat. I, 122: «carum ipsum verbum est amoris, ex quo amicitiae nomen est ductum; quam si ad fructum nostrum referemus, non ad illius commoda quem diligemus, non erit ista amicitia sed mercatura quaedam utilitatum suarum. prata et arva et pecudum greges diliguntur isto modo, quod fructus ex is capiuntur»):45

Rams de flores, f. 180v: Item el mismo en el libro de natura dominor[um] que cara cosa es esta paraula amor, cómo de aq[ue]sta paraula es tomado esti nombre amicitia o amigança; si nosotros la reboluemos no a prouecho de aquell que amamos o queremos mas a prouecho de nosotros mismos, digo q[ue] ya non es amigança, antes es mercadería de algunos prouechos nuestros. ${ }^{46}$

Glosa castellana, libro II, 3. parte, cap. XX: E aún dice más Tulio en el libro de la Natura de los Dioses, que muy caro es el nombre de amor onde toma raíz e nombre la amistanza; e la amistanza si la apropiáremos a nuestra pro o a nuestro bien e no al pro de nuestro amigo, no es amistanza verdadera, mas es mercaduría, ca con esta atijara cuidan los ommes sacar pro, mostrando ser por amigos e catándose siempre a lo suyo; e en esta manera aman las heredades e los ganados por el fruto e por el pro que llevan dellos. ${ }^{47}$

También se hace eco de nuestras obras la anónima traducción castellana, de finales del XIV, del De vita et moribus philosophorum de Walter de Burley. ${ }^{48}$ Un análisis más extenso y pormeno-

44 Cf. Glosa castellana al Regimiento de príncipes de Egidio Romano, ed. J. Beneyto, I-III, Madrid, 1947-48. El texto, de c. 1285 (cf. I, p. XVIII), conocido por D. Juan Manuel, López de Ayala, etc., estuvo, por ejemplo, en las bibliotecas del Príncipe de Viana y del marqués de Santillana, imprimiéndose en Barcelona en 1480; la Glosa, atribuida a fray Juan García de Castrojeriz y realizada por iniciativa del obispo de Osma, fue impresa en Sevilla en 1494.

45 El texto continúa diciendo: «hominum caritas et amicitia gratuita est; quanto igitur magis deorum, qui nulla re egentes et inter se diligunt et hominibus consulunt». El interés del pasaje ya lo había advertido Juan de Gales, que lo recoge en su Summa de regimine vitae humanae seu Margarita doctorum (Venecia, 1496, p. 55).

46 Es seguramente significativo que la misma lectura dominorum, por deorum, se encuentre en la obra de Eiximenis, Francesc, Dotzè llibre del Crestià II 2, ed. C. Wittlin (et al.), Gerona, 1987, de fines del XIV (cap. 759, p. 191): «La quarta misèria dels curials sí és falsa amistat, car, com diu Sèneca, aquí no y ha amistat sinó per lo profit. E per tal quant lo profit cesa e la amistat cesa, segons que posa Tullius, libro primo De natura dominorum, in fine, aquí amistat no és sinó mercaderia, ço és: fé.m axí e allí e fer-t'é semblant, e si no pots, vés-te-n a mal guany. Aquí la amistat segueix lo vent de la fortuna. E per tant quant negun vent no està ferm, axí aquí neguna amistat no serà jamés ferma». En la citada obra de Fernández de Heredia sè localizan además las siguientes referencias: (f. 127v) «Item el mismo dize en el libro II de natura de los dioses que quando sallie algun valient hombre desta vida el qual era stado prouechoso a la comunidat fazian dello remenbrança assi como si fuesse dios por tal que los otros tomassen buen coraçon de mantener el bien comun et que non dubdassen del prouecho de la comunidat» (Nat. I 38, 119, II 62); (f. 195r) «Item el mismo en el lib[r]o II de natura de los dioses dize ley es derecho scrito atorgado et cosa honesta et vedando la contraria» (Nat. I, 36: «naturalem legem divinam esse censet, eamque vim obtinere recta imperantem prohibentemque contraria, II 79:[...] lex, quae est recti praeceptio pravique depulsio).

47 En la misma obra se lee (libro III, 2. ${ }^{\text {a }}$., cap. XXIV): «ca Tulio declara la ley natural así: "Ley es muy alta e muy viva razón ingerida en la natura umanal, que nos manda las cosas que avemos de facer e nos defiende las contrarias o las que no havemos de facer". E aún dice así en el II. ${ }^{\circ}$ libro de la Natura de los Dioses, que ley es mandamiento de igualdad e de derecho e arredramiento de maldad e de tuerto».

$48 C f$. H. Knust, Gualteri Burlaei liber de vita et moribus philosophorum mit einer altspanischen Übersetzung der Eskurialbibliothek, Tubinga, 1886; sobre el texto cf. pp. 396-420. La traducción de la obra de Burley (1275-1337), que hizo uso a su vez de abundantes fuentes indirectas, se conserva en el Escor: h-III-1; su obra influyó en el marqués de 
rizado de este tipo de fuentes, que nos aportan los primeros ecos en castellano de la teología ciceroniana, demostraría a buen seguro cómo ésta circuló con frecuencia, de manera anónima, a través de una rica y variada tradición indirecta. ${ }^{49}$

En el siglo XV se produce un nuevo afloramiento de estas obras, coincidente con el repunte de la actividad traductora de los clásicos grecolatinos característico de la época e iniciado en la centuria anterior (López de Ayala, Juan de Mena, Díaz de Toledo, etc.), ${ }^{50}$ y basado igualmente en la estima tradicional hacia el Cicerón «cristiano» $^{51}$, simbiosis ideal de filosofía y retórica, de pensamiento y acción política. ${ }^{52}$ Enrique de Villena menciona en sus glosas a la Eneida nuestros tratados..$^{53}$ Alonso de Cartagena, traductor además de varias obras ciceronianas (siempre desde una pos-

Santillana y otros autores de la época; $c f$., por ejemplo, pp. 141: «Tullio dise en el libro primero de la divinacion que como Socrates estoviese en la carcel publica que dixo a Criton su familiar que dende en tercero dia avia de morir, y dixole que avia visto en suennos una fenbra de grant fermosura la qual le desia un verso de Omero en esta quisa: Tercia te Phthiae tenpestas leta locabit. Lo qual asy acaescio de Socrates como el avia dicho» (cf. Div. I, 52: «[...] «Socrates, cum esset in custodia publica, dicens Critoni suo familiari sibi post tertium diem esse moriendum; vidisse se in somnis pulchritudine eximia feminam, quae se nomine appellans diceret Homericum quendam eius modi versum: Tertia te Phthiae tempestas laeta locavit, quod ut est dictum sic scribitur contigisse»), 319: «De la natura de los dioses tres. De adevinacion dos. Del fado uno. De la creacion del mundo uno».

49 Podría citarse al respecto el caso de Valerio Flaco, ampliamente representado en nuestra tradición literaria desde el siglo XIV ( $c f$. G. Avenoza, «Traducciones de Valerio Máximo en la edad media hispánica», en L. Charlo (ed.), Reflexiones sobre la traducción. Actas del Primer Encuentro Interdisciplinar. Teoría y práctica de la traducción, Cádiz, del 29 de marzo al 1 de abril de 1993, Cádiz, 1994, pp. 167-179). Así, por ejemplo, en la Glosa castellana (libro II, 1. ${ }^{2}$ parte, cap. IX, pp. 48-49), se hace referencia al «libro VIII. ${ }^{\circ}$ de los Cuentos Maravillosos, en el capítulo.$^{\circ}$, do cuenta que un rey [...]», relatándose a continuación el episodio de las dos serpientes de Div. I, 36.

50 Cf., en general, Th. S. Beardsley, Hispano-classical translations printed between 1482 and 1699, Pittsburgh, 1970; P. Russell, Traducciones y traductores en la península ibérica (1400-1550), Bellaterra, 1985; R. Recio, (ed.), La traducción en España: ss. XIV-XVI, León, 1995.

51 Sobre S. Paciano (s. IV) cf. Maravall, o.c., pp. 276-277; sobre Eulogio de Córdoba (med. s. IX), que alabó el espíritu evangélico ciceroniano, cf. Guillén, «Cicerón en España», pp. 251, 254; según recuerda M. Morrás, Alonso de Cartagena. Libros de Tulio: De senetute, De los ofiçios, ed., pról. y notas de..., Alcalá de Henares, 1996, p. 27; Juan Alfonso de Zamora acepta «la bodega de Çiçerón» por ser «santa e incorruptible»; a propósito de Cartagena, $c f$. Guillén, «Cicerón en España», p. 257-258; a propósito de Vives, cf. Menéndez Pelayo, Bibliografía..., III, p. 73; K.A. Blüher, Séneca en España. Investigaciones sobre la recepción de Séneca en España desde el siglo XIII hasta el siglo XVII = Seneca in Spanien. Untersuchungen zur Geschichte der Seneca-Rezeption in Spanien vom 13. bis I7. Jahrhundert, Múnich, 1969), tr. J. Conde, ed. correg. y aum., 1983, pp. 156-157, 160.

52 Cf. D. Ynduráin, Humanismo y renacimiento en España, Madrid, 1994, pp. 219-225.

53 Cf. Enrique de Villena, Traducción y glosas de la Eneida. Libro primero; ed. y estudio de P. Cátedra, Salamanca, 1989, p. 51, gl. 57: «Este nombre de religio, segúnd dize Tulio, in libro De natura Deorum viene de religendo, que quiere dezir "muchas vezes tornar a leer" [...]» ( $c f$. Nat. II, 72; sobre la verosimilitud de la propuesta ciceroniana, frente a quienes relacionaban el término con religare, $c f$. G. Lieberg, "Considerazioni sull'etimologia e sul significato di religio», RFIC, 102 (1974), pp. 34-57); Traducción... Libro segundo, ed. y estudio de P. Cátedra, Salamanca, 1989, p. 66, gl. 373: «En estas palabras demuestra que la divinaçión, siquiere preçiençia de las cosas fazederas, viene al entendimiento umano por una manera de deseo fyrviente más de lo acostumbrado por yllustraçión divina, que exclaresçe la natural dispusiçión, suscitando la ydea universal que representa egualmente las venideras cosas como las presentes. Ansí lo ha dicho Tulio, in libro De divinaçione» (cf. Div. I, 127; II, 18, 117); ibídem, p. 83, gl. 380: «Dixéronle Minerva los griegos porque menguava de las dificultades con la soliçitud ho porque amenazava con el exerçiçio de las armas. E ansí lo ynterpretó este nombre Tulio, in libro De natura deorum, secundo. E en el libro terçero dixo que fueran muchas Minervas, de las quales cuenta dellas çinco; e dize que ésta que a las armas e a la sabieza era diputada fue la terçera» (cf. Nat. II, 67; III, 59); $c f$. igualmente R. Santiago, «Una biblioteca de clásicos grecolatinos en el siglo XV español», en M. Fernández-Galiano (ed.), Auguralia. Estudios de lenguas y literaturas griega y latina, Madrid, 1984, pp. 303-310, esp. 305. 
tura notablemente ortodoxa, pero no desvirtuadora) ${ }^{54}$ parece haber conocido al menos el De natura deorum y el Timeo. ${ }^{55}$ Pocos nombres más pueden citarse de nuestro «protohumanismo», ni siquiera en los ámbitos menos comprometidos desde el punto de vista ideológico, como el de la literatura mitológica, ${ }^{56}$ lo cual -insistimos- no significa que las obras en cuestión fuesen desconocidas entre nuestros eruditos o que su utilización fuese objeto de una especial repulsa. ${ }^{57}$

Son igualmente escasas, según nuestros datos, las referencias que pueden encontrarse en la literatura española del siglo XVI. Si bien el Cicerón maestro de retórica ejerció una poderosísima influencia en la península durante todo este $\operatorname{siglo},{ }^{58}$ dentro de una tendencia que ya arrancaba probablemente del XV, ${ }^{59}$ no parece haber tenido el mismo éxito la obra teológica del orador, que seguramente tampoco podía aportar ya demasiado al debate doctrinal de la época. Sin embargo, sabemos que fue conocida por autores como Fox Morcillo, ${ }^{60}$ Huarte de San Juan o Fernando de Herrera. ${ }^{61}$ En este contexto cabe recordar especialmente a fray Luis de Granada, que en su

54 Cf. Morrás, o.c., esp. pp. 7-42, 64-77; según esta autora, p. 69, «Cartagena mantiene una distancia crítica ante los clásicos, reflejada en la búsqueda de la máxima precisión léxica con el fin de evitar que se fundan conceptos de dos ámbitos diferenciados, el Cristianismo y la filosofía pagana». Sobre su recta comprensión del epicureísmo cf. A. Alonso, «Cristianismo y epicureísmo: Fray Alonso de Cartagena y el Libro de la vida bienaventurada», Dicenda, 3 (1984), pp. 191197. Sobre su debate con Bruni en torno a razón y elocuencia cf. O. di Camillo, El humanismo castellano del siglo XV, Valencia, 1976, pp. 218-224, L. Gil, Panorama social del humanismo español (1500-1800), Madrid, 1981, pp. 202-204.

55 Como observa Morrás, o.c., p. 28, Cartagena alude al De natura deorum en el manuscrito matritense 8241, f. 210r (a propósito del libro séptimo del De beneficiis senecano, se añade que los hombres indagan en las cosas divinales «contemplando y pensando en ellas, como dice Tulio en el libro de la natura de los dioses»; cf. Nat. II, 153); sobre su posible conocimiento del Timeo cf. A. Gómez Moreno, «Respuesta a la Qüestión fecha por el Marqués de Santillana», El Crotalón, 2 (1985), pp. 335-363, esp. 352.

56 Cabe destacar, en este sentido, la influencia del De genealogiis deorum de Boccaccio en obras como las de Alonso Fernández de Madrigal (Salamanca, 1507; sobre su uso del De natura deorum cf. P. Saquero y T. González Rolán, «Las Questiones sobre los dioses de los gentiles del Tostado: un documento importante sobre la presencia de G. Boccaccio en la literatura medieval española», CFC, 19 [1985], pp. 85-114, esp. 97), Martín de Ávila, Juan Pérez de Moya, fray Baltasar de Vitoria, etc.

57 Es el caso quizá de Nuño de Guzmán (med. XV), vivamente interesado en Cicerón y que pudo conocer nuestras obras a través, por ejemplo, de Manetti, que cita el De divinatione -directa o indirectamente- en su Laudatio Agnetis Numantinae: cf. J.N.H. Lawrance, Un episodio del proto-humanismo español. Tres opúsculos de Nuño de Guzmán y Giannozzo Manetti, Salamanca, 1989, p. 191 (Div. I, 56-57). Cabe recordar, en este sentido, que Nuño de Guzmán tradujo c. 1440 el De legendis gentilium libris de L. Bruni.

58 Cf., en general, Menéndez Pelayo, Bibliografia..., III, pp. 177-284 («Apuntes sobre el ciceronianismo en España, y sobre la influencia de Cicerón en la prosa latina de los humanistas españoles»); J.M. ${ }^{a}$ Núñez, El ciceronianismo en España, Valladolid, 1993; para épocas anteriores baste remitir al trabajo de Ch. Faulhaber, Latin rhetorical theory in thirteenth and fourteenth century Castile, Berkeley-Los Ángeles-Londres, 1972. Por lo demás, el diálogo como tal género literario tampoco parece haber recibido una influencia decisiva por la lectura de nuestros tratados ( $c f$. J. Gómez, El diálogo en el Renacimiento español, Madrid, 1988, pp. 94-101; A. Gómez Moreno, España y la Italia de los humanistas, «La recuperación del diálogo», pp. 196-214).

59 Cf. Morrás, o.c., p. 6, n. 4.

60 Autor de un meritorio comentario In Platonis Timaeum, Basilea, 1554.

61 Cf. F. Rico, El pequeño mundo del hombre. Varia fortuna de una idea en la cultura española, ed. correg. y aum., Madrid, 1986, p. 11, donde se citan sus Obras de Garcilaso de la Vega con anotaciones, Sevilla, 1580, p. 338: «[...] y así dice Tulio en el segundo De la naturaleza de los dioses: "El mundo es casi una casa común de dioses y hombres, y ciudad de unos y otros". Divídese en el mundo superior, que es el cielo (y, así, el mesmo Cicerón llamó -si no me acuerdo mal- "mundo luciente"), y en inferior, que es la tierra» (en alusión a Nat. II, 154: «est enim mundus quasi communis deorum atque hominum donus aut urbs utrorumque» y a Tim. 35 «ut hunc varietate distinctum [...] nos lucentem mundum nominaremus», respectivamente). 
Introducción del Símbolo de la Fe no dudó en utilizar ampliamente, con fines apologéticos, el De natura deorum, ${ }^{62}$ situándose así en una tendencia que se producía simultáneamente en otros países europeos. ${ }^{63}$ No podemos detenernos aquí en el gran interés que despertaron en la época otras muchas obras filosóficas ciceronianas. ${ }^{64}$

\section{CONCLUSIONES}

Los problemas que afectan a la pervivencia de la teología ciceroniana en España han de inscribirse, sin duda, en un marco general de extraordinaria complejidad, aquí aludido tan sólo, como es el de la delicada relación entre paganismo y cristianismo y el del redescubrimiento de los clásicos en el ámbito humanístico. En cualquier caso, creemos que de los datos expuestos anteriormente -y a expensas de lo que un análisis más riguroso que el nuestro pueda aportar- cabe deducir varias causas, de distinta naturaleza y seguramente coadyuvantes, para explicar el aparente desdén que parece detectarse en nuestra tradición hacia las obras ciceronianas en cuestión.

Desde el punto de vista puramente material, han podido intervenir factores como la relativa dificultad de acceso a un corpus teológico como el ciceroniano, parcialmente mutilado y aun así de considerable extensión ${ }^{65}$ no traducido sino saltuariamente y cuya obra más emblemática-De natura deorum- se encontraba estigmatizada en cierto modo desde el título.

A ello hay que añadir que la figura del Cicerón filosófico tampoco debía de resultar excesivamente familiar para nuestros eruditos medievales; mucho menos, en cualquier caso, que la de su sabio «rival» hispanorromano, Séneca, estoico a la sazón y sumamente apreciado siempre en la península, según demuestra su vastísima pervivencia. ${ }^{66}$ Cicerón, considerado ya un modelo indis-

62 Cf. fray Luis de Granada, Introducción del Símbolo de la Fe, ed. J. M. ${ }^{a}$ Balcells, Madrid, 1989, p. 55: «De este tratado ciceroniano [De natura deorum], que incluso da pie a todo un capítulo; el XXXI, titulado "Lo que dice Tulio de los sentidos exteriores de nuestro cuerpo", Luis de Granada extrae tres razones pàra probar la existencia de Dios, así la del consenso unánime de los pueblos en favor de la creencia en la divinidad, la de que hay una noción de la misma escrita en la mente humana, y la del orden y armonía cósmicas». En el autor influyó Cicerón a través de $S$. Ambrosio, según recuerda M. ${ }^{\mathrm{R}}$ R. Lida, Estudios sobre la literatura española del siglo XV, ed. Y. Malkiel, Madrid, 1977, p. 151.

63 El De natura deorum se utilizó ampliamente en Francia, a finales del XVI, para demostrar la existencia de Dios (cf. Blüher, o.c., pp. 349-350), así como en el XVII: por ejemplo, Pierre Lescalopier, que redacta c. 1630 un extenso comentario al De natura deorum (Humanitas theologica..., París, 1660; $c f$. H. Busson, La religion des classiques (16601685), París, 1948, p. 346).

64 Merecerían quizá especial atención los Academica, cuya pervivencia ha sido analizada por Ch. B. Schmitt, Cicero scepticus. A study of the influence of the Academica in the Renaissance, La Haya, 1972. Sobre la fortuna de la obra en España cf.. por ejemplo, J. Oroz, «Presencia de Cicerón en las Academica de Pedro de Valencia. Apuntes sobre el criterio de verdad», Helmantica, 106 (1984), pp. 5-50, R. Martínez Fernández, «Academica, ejemplo de didáctica en el humanismo renacentista», Helmantica, 139-141 (= M. ${ }^{a}$ R. Herrera, S. García-Jalón y M.A. Marcos (eds.), Thesauramata philologica Iosepho Orozio oblata, III, 1995, pp. 547-571). Según recuerda Rico, El pequeño mundo del hombre, p. 158, Francisco Sánchez fue uno de los lectores de la obra.

65 Cf. Pease, Nat., p. 58, n. 3, Morrás, o.c., p. 130.

66 Cf. Maravall, o.c., pp. 312-315, Blüher, o.c., esp. pp. 212-222 y 223-230. Como recuerda L. Holtz, «Prose et poésie latines tardives transmises aux Carolingiens par l'intermédiaire de l'Espagne», en J. Fontaine y Ch. Pellistrandi (eds.), L'Europe héritière de l'Espagne wisigothique. Colloque international du C.N.R.S. tenu à la Fondation Singer-Polignac (Paris, 14-16 mai 1990): Madrid, 1992, pp. 213-222, esp. 215, es muy probable que el origen hispano del autor también contribuyera -como en otros casos- a su especial arraigo en la península. 
cutible en el campo de la retórica, difícilmente podía llegar a serlo también en el del pensamiento, más aún cuando su ideario filosófico no estaba libre de sospecha, ni el dulce estilo en que se expresaba libre de recelos. ${ }^{67}$

Pero no cabe duda de que una de las razones que mejor explican la escasa atención prestada a la teología ciceroniana en España es la «ambigüedad» de sus contenidos. Su escepticismo y su carácter relativamente especulativo son factores que, sin duda, contribuyeron a cercenar la vitalidad de unas obras, que, en nuestra opinión, pese a no ser nunca proscritas, ni llegaron a ser especialmente apreciadas en la tradición hispánica por su valor intrínseco ni se consideraron en ningún momento insustituibles desde un punto de vista doctrinal o literario.
Ángel Escobar
Área de Filología Latina
Facultad de Filosofía y Letras
E-50009 ZARAGOZA

67 Ya que, como sugiere Morrás, o.c., pp. 41-42, la bondad del estilo ciceroniano podía, a su vez, invitar a leer los textos cristianos sólo en razón de su valor literario, extremo inaceptable desde un pensamiento cristiano. 